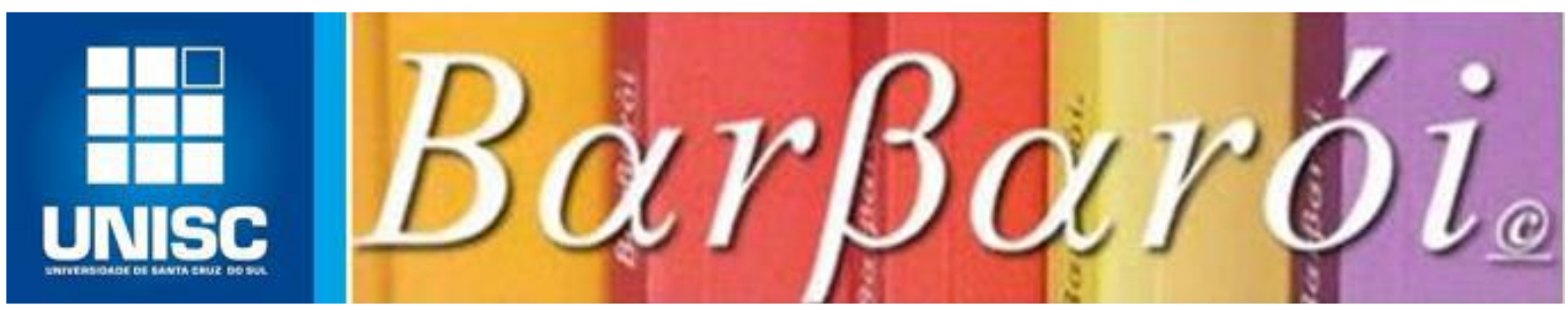

\title{
ÉTICA E POLÍTICAS DE PESQUISA NAS CIÊNCIAS HUMANAS E SOCIAIS
}

DOI: http://dx.doi.org/10.17058/barbaroi.v0i0.14793

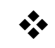 \\ Simone Maria Hüning \\ Instituto de Psicologia da Universidade Federal de Alagoas - UFAL - Brasil \\ $*$
}

\section{Resumo}

Diante da publicação da Resolução $n^{\circ}$ 510/2016 do Conselho Nacional de Saúde, que regulamenta a ética em pesquisa com seres humanos nas ciências humanas e sociais (CHS), este artigo propõe uma reflexão sobre os limites de se pensar a ética em pesquisa a partir da ênfase na regulamentação e no controle dos procedimentos metodológicos da pesquisa, dissociada de uma política epistemológica. Argumenta-se que nosso modelo de regulamentação atual reitera a prevalência de uma lógica positivista e individualista que tem sido, com frequência, restritiva de estratégias de pesquisa e, muitas vezes, levado ao esvaziamento da reflexão ética. Ademais, o engessamento em torno de procedimentos burocratizados e regulamentações pode também produzir um apagamento de diferenças entre distintas abordagens teóricas e epistemológicas nas CHS. Diante dessas questões são desenvolvidos dois argumentos principais: a) que a ética não é passível de institucionalização e normalização; e b) que não é possível dissociar ética da política epistemológica da pesquisa. Conclui-se afirmando a necessidade de um investimento intelectual e político na desnaturalização do modelo vigente de regulamentação. Nesse sentido, indica-se a importância da inclusão de outros atores em um diálogo mais amplo e horizontal sobre a ética em pesquisa. Sugere-se pensar a ética a partir de coletivos não institucionalizados que envolvam mais do que participantes e pesquisadores, e promover sua constituição como alternativa ao modelo naturalizado dos comitês. Simultaneamente, necessita-se ampliar a reflexão ético-política na formação e nas práticas de pesquisa para pensar os sentidos e limites da produção científica.

Palavras-chave: ética, pesquisa, ciências humanas e sociais

\section{Introdução}

Diante das recentes alterações na regulamentação da ética em pesquisa com seres humanos nas ciências humanas e sociais (CHS), este artigo propõe uma reflexão sobre os limites de se pensar a ética em pesquisa a partir da ênfase em sua institucionalização e no 
controle de procedimentos metodológicos da pesquisa de forma dissociada de posicionamentos epistemológicos e políticos na produção do conhecimento.

O ponto de partida para essa reflexão é a publicação da Resolução no 510/2016 do Conselho Nacional de Saúde (CNS) que

$$
\begin{aligned}
& \text { dispõe sobre as normas aplicáveis a pesquisas em Ciências Humanas e Sociais cujos } \\
& \text { procedimentos metodológicos envolvam a utilização de dados diretamente obtidos } \\
& \text { com os participantes ou de informações identificáveis ou que possam acarretar riscos } \\
& \text { maiores do que os existentes na vida cotidiana (CNS, 2016, s/p). }
\end{aligned}
$$

Apresentada como resultado de exaustivos debates realizados por representantes de associações científicas e consultores ad hoc em grupo de trabalho (GT) criado pela Comissão Nacional de Ética em Pesquisa (CONEP), em agosto de 2013, a nova resolução havia concentrado expectativas de que especificidades dessas áreas do conhecimento fossem contempladas. No entanto, com dois anos de vigência, poucas mudanças se efetivaram. A suspensão unilateral da continuidade da participação desses representantes na discussão da resolução complementar que trata da gradação e tipificação de risco - suspensão esta imposta pela CONEP - colocou em xeque a possibilidade de mudanças significativas no que concerne à operacionalização da nova resolução. A interrupção arbitrária do debate para a elaboração da resolução complementar sobre risco faz com que a resolução aprovada permaneça insuficiente na garantia das especificidades das pesquisas em ciências humanas e sociais.

Vários trabalhos têm colocado em análise avanços e limites da nova resolução e os impasses encontrados no seu processo de elaboração (DUARTE, 2015; FONSECA, 2015; SARTI, 2015; SARTI; PEREIRA; MEINERZ, 2017). Dentre as muitas publicações sobre o tema, Duarte (2017) nos apresenta uma cronologia detalhada da luta por uma regulamentação específica para as Ciências Humanas e Sociais na avaliação da ética na pesquisa com seres humanos. Nessas diferentes publicações, alguns dos aspectos apontados como avanços face às regulamentações anteriores, são o reconhecimento pelo sistema CEP/CONEP de que há especificidades para as pesquisas em ciências humanas e sociais, flexibilizações em relação aos modos e momentos de obtenção do consentimento dos participantes, a avaliação pelos CEPs apenas dos aspectos éticos e não do mérito científico dos projetos, a consideração de aspectos como desconfortos e constrangimentos gerados pela pesquisa aos participantes, bem como a responsabilização do pesquisador em relação a possíveis efeitos indesejáveis posteriores e relacionados à pesquisa. Como limites, colocam-se os obstáculos de efetivação dessas novas perspectivas na medida em que ainda dependem de avaliações feitas por comitês prioritariamente compostos por membros vinculados ao campo biomédico, a falta da instrumentos para sua operacionalização - como a adequação da Plataforma Brasil - e, 
principalmente, a não conclusão da resolução específica sobre tipificação e gradação de risco, prevista no artigo 21 da Resolução $n^{\circ}$ 510/2016 - CNS.

Em síntese, o que as análises mencionadas indicam é que, se, por um lado, podemos considerar que a publicação pelo CNS de uma resolução específica para as ciências humanas e sociais expressa o reconhecimento das especificidades desse conjunto de disciplinas, por outro, ela está longe de assegurar que tais especificidades se efetivem. Além disso, pode-se notar a abordagem que tenta garantir que a ética na pesquisa se efetive por imposição de uma norma jurídica. Um dos aspectos definidores dos limites da Resolução $n^{\circ}$ 510/2016 é que ela mantém a ênfase no procedimento metodológico da pesquisa como aquele que permite avaliar a definição e a gradação dos riscos aos participantes:

\begin{abstract}
Art. 18. Nos projetos de pesquisa em Ciências Humanas e Sociais, a definição e a gradação do risco resultam da apreciação dos seus procedimentos metodológicos e do seu potencial de causar danos maiores ao participante do que os existentes na vida cotidiana, em consonância com o caráter processual e dialogal dessas pesquisas (CNS, 2016, s/p).
\end{abstract}

Embora a nova regulamentação mencione o caráter processual e dialógico das pesquisas, permanece a necessidade da delimitação a priori de suas etapas e procedimentos metodológicos, sobre os quais incidiria a possibilidade de avaliação dos riscos e, consequentemente, da ética da pesquisa. Tal determinação vincula-se a, pelo menos, dois aspectos problemáticos.

O primeiro deles é a caracterização daquilo que é considerado ciência (ou conhecimento válido) a partir de uma primazia do método sobre outras dimensões da pesquisa. Herança do pensamento positivista, tal postura opera a partir da suposição da neutralidade que dissocia ciência e ética e julga que o conhecimento pode ser hierarquizado a partir da avaliação do rigor metodológico adotado. Nessa perspectiva, as práticas científicas, consideradas um fim em si, só teriam que responder a si mesmas a partir da neutralidade, generalização e bom uso dos métodos científicos.

O segundo aspecto é o tratamento da ética a partir da noção de risco ao participante, em detrimento de outros aspectos da produção do conhecimento. Se a pesquisa é um processo que não se dá numa dimensão apartada do mundo social, político, econômico, cultural e assim por diante, a interface com a ética não pode ser localizada em um momento estanque da pesquisa - tal como o da execução de um procedimento metodológico junto a um participante -, tampouco ancorar-se apenas na avaliação da imposição de risco. A emergência de problemas éticos pode ocorrer tanto no processo de realização da pesquisa como na divulgação de resultados (SEVERINO, 2015). 
Outros problemas pontuados quando se discute ética na pesquisa são: plágios, autoplágios, falseamentos de dados, favorecimento de pares em processos editoriais, inclusão ou sonegação de autorias em trabalhos coletivos, estigmatização de grupos-alvo de pesquisas, presença de interesses econômicos, entre outros (FONSECA, 2015; OLIVEIRA, 2015; SEVERINO, 2015; HARAYAMA, 2017). Dessas questões, à parte do cuidado com a estigmatização, que aparece no artigo $3^{\circ}$ da Resolução 510/2016 dentre os princípios éticos das pesquisas em CHS - "IX - compromisso de todos os envolvidos na pesquisa de não criar, manter ou ampliar as situações de risco ou vulnerabilidade para indivíduos e coletividades, nem acentuar o estigma, o preconceito ou a discriminação" (CNS, 2016, s/p) - as demais não constam do texto da nova resolução. Do mesmo modo, não é discutida a ética em pesquisas que não envolvem participantes diretos nos procedimentos medotológicos. Aceitando-se temporariamente que a ética pudesse ser regulada por esse tipo de dispositivo, caberia questionar sobre esses outros elementos que também constituem questões éticas, bem como se pesquisas que não envolvem participantes diretos ou informações identificáveis não teriam aspectos éticos a serem considerados.

Assim, a noção de ética em pesquisa que permite o desenvolvimento de nossa reflexão coloca-a para muito além do controle ou evitação do risco resultante dos "procedimentos metodológicos e do seu potencial de causar danos maiores ao participante do que os existentes na vida cotidiana" (CNS, 2016, s/p). Pensa-se a ética, para além de uma preocupação com todos os sujeitos envolvidos direta ou indiretamente - não pela sua condição de participantes, mas pelo respeito à dignidade e à vida humana -, como o compromisso científico, ético e político da pesquisa, deslocando as exigências de cuidado e proteção que estão colocadas até o momento apenas para com os participantes diretos das investigações. Nesse sentido, sinalizando que não é possível pensar unicamente a partir do risco para o indivíduo, Severino (2015) chama a atenção que "o respeito ou o desrespeito a determinados princípios e direitos respingam simultaneamente no todo da sociedade, nas instituições enquanto entidades sociais e em todos aqueles que indiretamente colaboram com a realização da pesquisa ou que são seus destinatários" (SEVERINO, 2015, p. 789).

Feitas essas considerações, propõe-se ampliar a reflexão sobre a ética na pesquisa em CHS para além do que cabe na prescrição de uma resolução, tensionando o modo como a regulamentação adotada pela CONEP se operacionaliza pelos CEPs. Se normas jurídicas podem garantir alguma proteção, elas certamente não dão conta do que vem a ser uma reflexão ou uma relação ética entre sujeitos envolvidos em uma pesquisa, e tampouco podem ser reduzidas à avaliação do risco a partir do método. Isso é particularmente importante Barbarói, Santa Cruz do Sul, n. 56, p.<84-103>, jan./jun. 2020 
quando falamos de campos de produção do conhecimento que não se conformam a perspectivas positivistas de ciência. É frágil a ideia de que a ética possa ser assegurada no plano jurídico contratual previsto pelo modo de funcionamento das resoluções da CONEP e dos comitês de ética em pesquisa. Desse modo, discute-se que a Resolução no 510/2016 CNS não tem como abarcar a complexidade das questões éticas enfrentadas pelas ciências humanas e sociais. São desenvolvidos dois argumentos principais: a) a ética não é passível de institucionalização e normalização; e b) não é possível dissociar ética da política epistemológica da pesquisa. Ao final, afirma-se a necessidade de um investimento intelectual e político para desnaturalizar o modelo vigente e pensar alternativas para a promoção da ética na pesquisa com seres humanos, particularmente nas ciências humanas e sociais.

\section{Guardiões da ética}

Atualmente são abundantes as publicações acadêmicas que apresentam e discutem a história da criação dos comitês de ética em pesquisa, da emergência das preocupações com violações de direitos e danos a participantes a partir de experimentos biomédicos, e de como tais preocupações começaram a ser traduzidas em regulamentações sobre a ética em pesquisa com seres humanos, no contexto internacional e nacional. Dada a existência desse vasto material, aqui serão retomados apenas brevemente alguns desses trabalhos recorrendo sobretudo aos que, ao mesmo tempo em que aludem aos processos históricos situando as condições para o modelo vigente, dialogam com os dilemas contemporâneos enfrentados em nosso país.

No Brasil, as regulamentações da ética em pesquisa com seres humanos estão vinculadas ao chamado sistema de Comitês de Ética em Pesquisa/Comissão Nacional de Ética em Pesquisa/Ministério da Saúde (CEP/CONEP/MS) e, a despeito das preocupações utilizadas para justificá-las, são notadamente marcadas pelo que Duarte (2015) chama de “imperialismo bioético" (DUARTE, 2015, p. 31). Tal imperialismo insiste em impor a pesquisadores de diferentes áreas do conhecimento reducionismos e essencialismos biomédicos, forçando um "monopólio da reflexão e intervenção política sobre a ética em pesquisa" (DUARTE, 2015, p. 42).

Fonseca (2015) faz uma esclarecedora análise do modo de estruturação dos CEPs e do processo que levou à “expansão sorrateira” (FONSECA, 2015, p. 354) do seu alcance do campo biomédico para o campo das CHS. Para isso, retoma elementos históricos, políticos e econômicos do processo de surgimento dos CEPs nos Estados Unidos da América, colocando em análise atores, acontecimentos e interesses envolvidos, bem como dilemas decorrentes 
desse tipo de estruturação. Ela também contrapõe o modelo legalista de regulamentação, que se desenvolveu nos EUA e nos serviu de inspiração, ao modelo europeu. Ao passo que o primeiro levou a uma abordagem focada no risco individual, na Europa a atenção foi voltada para as implicações sociais e coletivas da pesquisa (FONSECA, 2015).

Nesse trabalho, Fonseca (2015) aponta ainda para como os comitês de ética configuraram-se como espaços de operação de um conjunto de procedimentos burocráticos, em vez de operarem a partir de princípios éticos. Traz o alerta de que "identificar ou propor soluções para 'aperfeiçoar' os atuais CEPs sem questionar a premissa fundante (de que esses comitês são o lugar 'lógico' para garantir o proceder ético da ciência) arrisca contribuir para a naturalização do modelo" (FONSECA, 2015, p. 336). O questionamento de tal premissa está também na base da discussão de Silveira e Hüning (2010), que defendem a inviabilidade de que a regulação ética se dê por meio de comitês, independente do esforço, da qualificação e boa vontade de seus membros. "O que a estruturação de um comitê de responsáveis produz é uma perigosa fragmentação que dissocia a ética da ação humana ordinária.” (SILVEIRA; HÜNING, 2010, p. 390).

Como comitês, tais dispositivos operam necessariamente em instâncias burocratizadas separadas das diferentes comunidades científicas, da vida social cotidiana, do contexto de realização da pesquisa, da singularidade das situações e das relações entre atores envolvidos (pesquisadores e participantes) (SILVEIRA; HÜNING, 2010). Nada podem saber, portanto, do processo vivo em que se estabelece a relação de construção e execução da pesquisa, para além daquilo que cabe nos formulários e protocolos de avaliação.

Outra contribuição importante para essa reflexão é apresentada por Harayama (2017), que define o sistema CEP/CONEP como "um sistema que mede a ética individual do pesquisador por meio de uma gestão do risco" (HARAYAMA, 2017, p. 27). Sua característica principal, segundo o autor, "é a conjugação de um modelo de gestão do conhecimento, em nome da defesa do participante da pesquisa, intermediado pela estética da cultura da avaliação e da retórica da sociedade do risco" (HARAYAMA, 2017, p. 28). Em sua análise, o autor conecta a vinculação do sistema instituído no Brasil à lógica neoliberal, que, por sua vez, traz também impasses éticos para a prática da pesquisa. A recente resolução que regulamenta a ética em pesquisa com seres humanos nas CHS, além de não romper com a vinculação mencionada, reitera a prevalência de uma lógica do indivíduo na pesquisa: uma ética individual do pesquisador - tutelada pelas avaliações dos comitês -, que deve ser protetora do risco individual ao participante.

Acompanhar o percurso percorrido pelos autores supracitados é um passo fundamental Barbarói, Santa Cruz do Sul, n. 56, p.<84-103>,jan./jun. 2020 
para questionarmos a obviedade do modelo a que estamos submetidos no Brasil. Na atualidade, o risco de naturalização desse modelo se consolida e amplia por outra naturalização em curso no país: a de que cabe ao Ministério da Saúde a autoridade para legislar sobre a ética em pesquisa com seres humanos, mesmo quando não se trata de pesquisas na área da saúde. Ainda que muito atentos a essas questões - sinalizadas frequentemente por vários dos representantes das CHS que compuseram o GT para elaboração da Resolução n ${ }^{0}$ 510/2016/CNS, bem como por associações de pesquisa das CHS -, foi no sentido da construção de uma resolução específica vinculada ao sistema CEP/CONEP/MS que grande parte dos esforços foi investida nos últimos anos.

Sarti (2015) aborda a mobilização do Fórum das Associações de Ciências Humanas e Sociais e Sociais Aplicadas (FCHSSA), criado em 2013, sobre as questões da regulamentação da ética em pesquisa no Brasil. A autora registra a busca, pelo FCHSSA, da elaboração de regulamentação específica para as CHS fora do domínio do Ministério da Saúde, possivelmente vinculada ao Ministério da Ciência, Tecnologia e Inovação (SARTI, 2015). Segundo Sarti (2015), que nos conta detalhes desse percurso e seus percalços, o aceite das associações para participar do GT a convite da CONEP, mantendo a regulamentação da ética nas pesquisas em CHS vinculada ao MS, decorreu do "desalento [e] da falta de alternativas naquele momento" (SARTI, 2015, p. 83), não se abandonando, no entanto, a busca de alternativas a esse sistema, que hoje se reaviva diante do não cumprimento das etapas que deveriam suceder a aprovação da resolução 510/2016. Em outro trabalho, Sarti, Pereira e Meinerz (2017) registram que o "processo de elaboração da 510/2016 refletiu toda a controvérsia e o enquadramento político dentro do qual se desenrola o conflito em torno da demanda das CHS de retirarem a regulamentação da ética em pesquisa do Ministério da Saúde” (SARTI, PEREIRA e MEINERZ, 2017, p.10).

Frente aos impasses encontrados na busca de uma alternativa ao MS e o reconhecimento da importância de uma instância à qual seriam remetidas as questões relativas à ética em pesquisa, deu-se prosseguimento ao trabalho do GT de elaboração da resolução específica para as CHS, vinculado à CONEP. O processo, contudo, seguiu sempre intensamente permeado por conflitos, como expressa a Carta aberta de resposta à carta da CONEP, publicada em 02 de fevereiro de 2015 (GRUPO DE TRABALHO, 2015). O encerramento da primeira etapa dessa tarefa, com publicação da resolução 510/2016, não dirimiu os desacordos entre representantes das CHS e representantes institucionais da CONEP. 
O desdobramento final de afastamento dos representantes das associações de CHS da conclusão do trabalho de elaboração da minuta de tipificação e gradação de risco reitera esses conflitos, a naturalização do modelo até então adotado pelo sistema CEP/CONEP e a demarcação de um campo de poder político e institucional. Quando colocam sua ênfase de ação no controle, as instâncias responsáveis por fazer cumprir uma regulamentação posicionam-se numa disputa de poderes. É interessante, nesse sentido, a análise provocativa feita por Silveira (2013) sobre o lugar de superioridade em que se colocam os Comitês de Ética em Pesquisa no Brasil. Para o autor, eles são "figuras do autoritarismo político do Estado brasileiro tentando gerenciar a vida ética de seus cidadãos” (SILVEIRA, 2013, p. 172). Isso porque expressariam, ou compactuações, ou posturas de tolerância que, como efeito, destituem o espaço para o diálogo e a busca da igualdade entre pesquisadores e participantes.

Cabe aqui uma ressalva sobre as assimetrias nas relações de poder que podem se estabelecer entre esses agentes das pesquisas (sobretudo entre participantes e pesquisadores), especialmente no campo biomédico onde intervenções diretas sobre o corpo e as condições de saúde dos participantes estão no centro das pesquisas. A própria emergência das regulações bioéticas decorre dos danos causados a participantes de pesquisas nas quais sobrepuseram-se interesses econômicos, ou ainda a simples noção de que em nome do conhecimento gerado tais pesquisas seriam legítimas. Contudo, no que concerne às CHS e no tipo de relação e intervenção que se estabelece entre pesquisadores e participantes nestas investigações, a delegação da reflexão ética aos comitês enfraquece a construção da relação ética entre esses atores.

Para muitos pesquisadores das CHS, os efeitos da imposição da regulamentação da ética a partir da noção de risco individual têm sido, com frequência, restritivos de práticas de pesquisa. Como resultado, muita energia tem sido dispendida para que se consiga 'convencer' CEPs sobre o caráter ético de pesquisas que nem sempre conseguem atender aos elementos protocolares inspirados no modelo bioético. Essa situação evidencia que há uma diferença fundamental entre o que é ética e o que é regulamentação jurídica. Se a ética é compreendida como reflexão singular que só pode ocorrer diante de situações que se colocam aos sujeitos éticos no exercício da vida cotidiana, não é possível prevê-la, prescrevê-la ou garanti-la por meio de normalização. Ética é exatamente o que resiste à possibilidade de uma captura que engessa e padroniza a ação. É também o que escapa à possibilidade de uma terceirização de sua reflexão para os comitês. Conforme define Sarti (2015), 
aquele que desobedece, sendo a desobediência um exercício ético (SARTI, 2015, p. $87)$.

Quando a ética na pesquisa passa a ser tratada prioritariamente com referência a protocolos e instâncias institucionais burocatizadas, o efeito paradoxal é o esvaziamento da reflexão ética sobre os aspectos mais amplos da pesquisa, conduzindo à obediência ou desobediência da regulamentação. No contexto atual, em que a lógica neoliberal compõe de modo significativo o cotidiano da pesquisa acadêmica, mesmo tal obediência pode, muitas vezes, ligar-se meramente a questões de ordem produtivista e econômica, tais como obter financiamentos e conseguir publicar os resultados da pesquisa.

Adensando as análises sobre os limites desse tipo de regulação, Duarte (2015) destaca que nas CHS, em particular, não se pode perder de vista o caráter dialógico e negociado da pesquisa, que expressa, portanto, um "processo social e não de um contrato jurídico" (DUARTE, 2015, p.35). Por isso,

a avaliação da ética em pesquisa tal como ela se apresenta retratada em um "projeto" de pesquisa não é certamente a melhor maneira de fazê-la - nas CHS. Dadas as características de processualidade e dialogicidade referidas, qualquer afirmação preliminar, ex ante, só poderá consistir em frágil pressuposição, em declaração de boas intenções, mais do que de antevisão dos efetivos procedimentos (DUARTE, 2015, p.36).

Ademais, o engessamento em torno de procedimentos burrocratizados e regulamentações, tais como temos no Brasil, pode também produzir um alisamento e apagamento de diferenças importantes entre distintas abordagens teóricas e epistemológicas nas ciências humanas. Tal alisamento e apagamento de diferenças produzem-se pela imposição de um modelo dominante de pesquisa e produção de conhecimentos compatível com os protocolos padronizados de avaliação dos chamados aspectos éticos da pesquisa. No sistema CEP/CONEP, a associação da avaliação ética aos princípios bioéticos e biomédicos orientou e naturalizou a forma de se pensar a ética (SARTI; PEREIRA; MEINERZ, 2017) e também a pesquisa. Como consequência, pesquisadores passam a apresentar procedimentos muitas vezes pouco realistas ou pertinentes à pesquisa e à perspectiva epsistemológica adotada, para obter a aprovação de seus projetos. Tais procedimentos tentam, em geral, corresponder a um modelo naturalizado de pesquisa, onde hipóteses, estratégias metodológicas, número de participantes e até mesmo os questionamentos que serão feitos devem ser pré-determinados. Ilustram essas situações propostas de pesquisas que se propõem dialógicas e processuais - para as quais é, portanto, inviável delimitar de antemão todas as suas estratégias metodológicas -, que retornam dos comitês de ética com pendências por não apresentarem número exato ou considerado satisfatório de participantes. Uma infinidade de Barbarói, Santa Cruz do Sul, n. 56, p.<84-103>,jan./jun. 2020 
estratégias inovadoras de produção de dados precisam ser, muitas vezes, dissimuladas, para serem reconhecidas como procedimentos considerados legítimos, adequados e éticos. É comum que formas não convencionais de produção de pesquisa com participantes sejam nomeadas em termos de técnicas tradicionais, forçando que, por exemplo, conversas espontâneas ou rodas de conversa sejam chamadas nesses projetos de entrevistas abertas ou grupos focais, que nada expressam daquilo a que efetivamente se dispõe a pesquisa.

Assim, a um conjunto amplo de disciplinas que operam com perspectivas epistemológicas não consensuais, força-se, a partir do modo de operar desse dispositivo de controle em que se constituíram os CEPs, o apagamento de diferenças e especificidades que imbricam epistemologia, ética e políticas de pesquisa. Em nome da ética impõem-se modelos de controle de procedimentos de pesquisa que inviabilizam ou dificultam certas práticas de produção de conhecimento - principalmente aquelas que se distanciam do positivismo. Essas práticas não podem ser tomadas a priori como éticas ou antiéticas, mas precisam ter espaço legítimo para que sejam produzidas e refletidas quanto a esse aspecto. O que se afirma, assim, é que não é possível uma ética descolada da vida e da singularidade das ações humanas, inclusive das ações de conhecer e pesquisar, sendo, portanto, ilusória a sensação de que os CEPs poderiam zelar pela ética na pesquisa.

Tomar a ética dos processsos de pesquisa como exercício cotidiano do pesquisador e da sociedade de forma mais ampla, parece ser o modo mais coerente de buscar organicicidade desse tipo de avaliação e regulação. Propõe-se com isso um efetivo comprometimento e responsabilização dos pesquisadores sobre a ética de suas pesquisas, que permitiria enfrentar possíveis acusações de que se pretende o afrouxamento do princípio de que o pesquisador deve zelar pela proteção ao participante da pesquisa, a elaboração de conceitos mais ou menos elásticos da ética, ou ainda uma maior permissividade em relação a procedimentos de pesquisa.

\section{Políticas de pesquisa}

Nossos guardiões da ética podem efetivamente empenhar grande esforço na proteção de boas práticas científicas e dos participantes da pesquisa. Deve-se registrar inclusive que esse esforço é, frequentemente, uma atribuição que se soma à rotina de trabalho de docentes e pesquisadores, demandando grande disponibilidade para a execução dessa tarefa. Contudo, como sinalizam as análises já percorridas, o modo de operação institucionalizado a partir da lógica dos comitês de ética e a própria orientação da resolução recém-aprovada não resolvem algumas dificuldades desse processo. Uma dessas dificuldades decorre da diversidade Barbarói, Santa Cruz do Sul, n. 56, p.<84-103>, jan./jun. 2020 
epistemológica nas CHS e sua dissonância com os paradimas positivistas de ciência. Por mais que possamos hoje falar de uma abertura epistemológica que ressignifica o que é a ciência e o que é o conhecimento válido, vemos na trajetória da regulamentação da ética em pesquisa, porque vinculada ao paradigma biomédico, a prevalência de pressupostos positivistas.

Mesmo a nova resolução, que intenta atender a especificidades das ciências humanas e sociais, segue herdeira dessa tradição biomédica ao operar a partir da avaliação do risco individual, negligenciando a amplitude da ética como dimensão intrínseca de qualquer etapa da produção do conhecimento. Essa herança certamente não decorre de mero descuido dos envolvidos em sua elaboração, mas sobretudo dos embates e disputas de poder daqueles que detêm a guarda da ética em pesquisa com seres humanos e pretendem mantê-la vinculada ao Ministério da Saúde. Segue, portanto, operando com uma perspectiva de ciência que, afirmando-se neutra, baliza sua validade a partir de procedimentos metodológicos e seu potencial de generalização, dissociando-se da esfera política. E aí esbarramos em um grande problema, pois não é possível dissociar análise ética da posição política e epistemológica adotada.

A ampliação do campo de possibilidades nos modos de se produzir conhecimentos e o reconhecimento da dimensão política dessas práticas reconfiguram a reflexão ética na ciência. Assim, quando pensamos sobre ética em pesquisa é importante pensar quais valores norteiam nossa produção de conhecimento, nossos modos de fazer pesquisa e quais as epistemologias legitimadas ou desqualificadas. É preciso colocar em questão como produzimos e operamos com nossas políticas de pesquisa, compreendidas para muito além das formas como o Estado ou as agências fomentam, financiam, regulam ou avaliam a produção científica. São políticas de pesquisa as formas como nos relacionamos com o conhecimento e o mundo cotidiano, com as estratégias de investigação, escrita e divulgação, com os atores envolvidos, com a sociedade, com a delimitação das questões que decidimos ser relevantes de estudar, os efeitos e implicações de nossas pesquisas, e assim por diante. Trata-se de colocar o conhecimento numa relação ético-política com a vida, para muito além das regras que normalizam os discursos e práticas acadêmico-científicas.

Nessa relação, concernem à ética também as questões sobre: o que, onde, como, com quem, quando, por que, para quem pesquisar, do mesmo modo que a reflexão sobre aquilo que não é investido de interesse ou legitimidade na produção acadêmica. A definição de política apresentada por Souza (2004) nos ajuda a compor a ideia da relação da ética com as políticas de pesquisa. Para o autor, política diz respeito a formas éticas de convivência que permitam "a cada ser relacionar-se o mais saudavelmente possível com cada outro ser" Barbarói, Santa Cruz do Sul, n. 56, p.<84-103>, jan./jun. 2020 
(SOUZA, 2004, p. 30). A ética é a "consciência da ciência (...) a reflexão sobre seu 'antes', 'durante' e 'depois', seu sentido humano e histórico" (SOUZA, 2004, p. 38). Como tal, questiona a hierarquia entre ciência e ética, que caracteriza o positivismo científico. É éticopolítica, portanto, nossa posição epistemológica, ou o modo como relacionamos o conhecimento que produzimos com o mundo cotidiano e as pessoas que o habitam.

Todo esse conjunto de elementos define e situa nossas políticas epistemológicas de pesquisa. Nessa perspectiva, a análise da ética vai vincular-se a aspectos que nem sempre podem ser antecipados e a cujas respostas não se consegue chegar por procedimentos protocolares padronizados, porque necessita ser pensada na relação. Se se trata de uma relação ética, ela deve dar-se na singularidade de cada um dos encontros provocados pela prática e interesses da pesquisa. Porém, submetidos ao sistema vigente, mesmo antes de se conseguir colocar em movimentos essas práticas e políticas de pesquisa, seguimos esbarrando na necessidade de previsibilidade do que muitas vezes é imprevisível e de uma mensuração da relevância do conhecimento pelo pressuposto da generalização. Exemplifico com uma das questões frequentemente levantada nos debates realizados no GT para a elaboração da resolução 510/2016 do CNS.

Na relutância de aceitar a desvinculação da avaliação do mérito científico da análise ética, utilizava-se, dentre outros, o argumento sobre o perigo da futilidade da pesquisa. Defensores de que os CEPs realizassem também a avaliação científica dos projetos arguiam que pesquisas fúteis - dentre as quais enquadravam desde pesquisas com 'temas/objetivos irrelevantes', 'amostras insuficientes' ou 'metodologias não científicas'-, não seriam pesquisas éticas, tampouco o seriam pesquisas que não produzissem resultados científicos válidos, relevantes ou generalizáveis. Aqui está o problema do apagamento das diferenças e da imposição de um modelo de ciência: qual é o parâmetro que pode ser institucionalizado numa resolução e operado por um comitê, ambos externos à situação da pesquisa, para afirmar a futilidade ou a relevância de uma pesquisa? Qual o parâmetro epistemológico a ser adotado pelo grupo que constitui tais comitês para o estabelecimento de uma legitimidade para modos de produção de conhecimento e resultados, considerados válidos, relevantes ou científicos? Que política científica e que tipo de verdade perpassam essas concepções?

Note-se que, na perspectiva aqui assumida, a afirmação de que nossas práticas de pesquisa são ações políticas, que a ética é parte indissociável de nossas políticas de pesquisa concernindo a todas as suas etapas, evidentemente coloca em questão a relevância do conhecimento produzido, de tal modo que essa reflexão não pode ser delegada a terceiros. Não cabe a um comitê de ética legislar sobre que tipos de conhecimentos são válidos ou não, Barbarói, Santa Cruz do Sul, n. 56, p.<84-103>, jan./jun. 2020 
na medida em que as próprias instituições científicas já possuem uma série de dispositivos que operam essa avaliação a partir de seus pares e comunidades acadêmicas.

Assim, um dos aspectos que é considerado um avanço na resolução 510/2016 do CNS, que retira do sistema CEP/CONEP a autoridade para a avaliação científica e metodológica dos projetos, pode ser visto não só como uma conquista, mas também como a expressão de um sistema que sempre tentou impor, junto com uma regulação para a proteção ao participante, uma política de pesquisa. Quando é necessário afirmar na própria resolução que não compete aos comitês de ética a avaliação dos aspectos teóricos e metodológicos dos projetos, evidencia-se a ambição desse sistema de operar como um regulador das formas de produzir conhecimento, bem como o receio de que se perpetuem as experiências, até então comuns entre pesquisadores das $\mathrm{CHS}$, de terem que adequar suas propostas a um tipo de discurso científico hegemônico.

O problema aqui não está em que se pense a ética na pesquisa simultaneamente aos seus aspectos científicos ou epistemológicos, o que até poderia ser desejável desde que essas dimensões fossem efetivamente consideradas a partir de uma perspectiva ético-política da ciência. A questão é que primeiro coloca-se a avaliação ética como um momento fraturado de uma reflexão mais ampla sobre a pesquisa; então, delega-se essa avaliação aos comitês, instâncias especiais e específicas para esse fim, que frequentemente extrapolando sua competência institucional, decidem legislar sobre o mérito das propostas sem a consideração da amplitude de perspectivas epistemológicas nas CHS.

O dimensionamento exacerbado das instâncias de formulação e operação da regulamentação da ética na pesquisa com seres humanos, no debate sobre a ética no Brasil, deu-se em grande parte pelos desconfortos e entraves que estas impuseram, particularmente às CHS. A ênfase na abordagem da ética a partir das resoluções, dos protocolos, dos termos de consentimento etc., tem gerado, em muitos espaços acadêmicos, certa 'aversão' ao debate ético, que passou a ser reduzido a essas instâncias reguladoras com frequencia vividas como entraves à pesquisa. Da busca por um maior controle e garantia da ética na pesquisa, emergiu o efeito colateral do reducionismo e da burocratização. Concedemos, assim, ao sistema CEP/CONEP o poder de direcionar nossas concepções de ética e de pesquisa, colocando em segundo plano reflexões mais amplas sobre a ética no fazer científico. Como bem aponta Harayama (2017), tal desvio de foco nos coloca o risco de nos distanciarmos do "debate sobre os desafios em como criar mecanismos para minimizar os impactos negativos da prática da pesquisa nas populações estudadas, ou mesmo na criação de estratégias para a prática reflexiva do pesquisador na contemporaneidade." (HARAYAMA, 2017, p.26)

Barbarói, Santa Cruz do Sul, n. 56, p.<84-103>, jan./jun. 2020 
Os debates epistemológicos contemporâneos têm enfatizado que políticas de pesquisa que refutam noções do conhecimento como sinônimos de progresso, de universalização ou como passíveis de hierarquização, por si sós, engendram outra reflexão sobre a ética na pesquisa. Isso não coloca tais perspectivas num patamar ético superior, porém assinala a inextricabilidade dessa reflexão na produção do conhecimento e, assim, responsabiliza pesquisadores e suas comunidades científicas a responderem pela ética e pela proteção aos participantes, sem a mediação da burocracia dos comitês.

\section{Outros caminhos possíveis, ou, o que se pode concluir}

Como concluir uma reflexão que tem como pauta a ética na pesquisa? Ética refere-se sobretudo a um elemento vivo que se compõe na complexa rede de relações entre humanos e não humanos: transformações políticas e sociais; inovações das tecnologias e o que elas tornam possível na produção de conhecimentos; modificações das relações a partir de novas possibilidades tecnológicas; o que se torna aceitável nessas relações com o outro e com as tecnologias; as maneiras como se busca regular essas relações; reflexões filosóficas e epistemológicas; etc. Esse caráter dinâmico torna limitada a possibilidade de conclusões absolutas ou definitivas em torno do tema da ética na pesquisa nas ciências humanas e sociais. Contudo, diante do objetivo proposto para esse artigo - realizar uma reflexão sobre os limites de se pensar a ética em pesquisa a partir da ênfase na regulamentação e no controle dos procedimentos metodológicos da pesquisa, dissociada de uma política epistemológica -, algumas considerações, a título de conclusão, são sistematizadas a seguir. Estas buscam reafirmar: a indissociabilidade da ética da produção do conhecimento; a limitação de se pensar a ética por procedimentos metodológicos ou regulamentações; a viabilidade de se propor outros modelos de regulação e formas de investimento na reflexão e promoção da ética na pesquisa em ciências humanas e sociais, que ultrapassem a participação de especialistas e considerem a sociedade de modo mais amplo; e, por fim, a desejabilidade de uma estreita conexão da ética e das políticas de pesquisa com a vida cotidiana. Como base para todas as considerações que seguem, reitera-se que a reflexão ética na pesquisa é imprescindível tanto na busca da proteção aos participantes e sociedade quanto para nos fornecer balizadores de nossa prática como pesquisadores.

Neste trabalho, argumentou-se em favor de uma distinção entre o que significa uma reflexão ético-política, que deveria ser constituinte de qualquer prática científica, e um modelo de regulação estruturado a partir dos CEPs. Considerando tal distinção, conclui-se que a publicação de uma resolução específica para as CHS está longe de nos oferecer um Barbarói, Santa Cruz do Sul, n. 56, p.<84-103>,jan./jun. 2020 
dispositivo eficiente para a regulamentação da ética em pesquisa - fundamentalmente porque ética não pode ser prescrição jurídica -, bem como de atender efetivamente às especificidades de tão amplo campo do conhecimento, uma vez que tal resolução ainda está muito vinculada a um positivismo científico.

Nesse sentido, embora não restem dúvidas de que procedimentos guardam estreita relação com a possibilidade de riscos aos participantes das pesquisa e, portanto, são pertinentes e necessários para a apreciação de seus aspectos éticos, a abordagem da ética pela noção de risco individual, a redução de risco aos procedimentos metodológicos e a atribuição dessa avaliação a um comitê de especialistas obscurecem outras dimensões da pesquisa que se vinculam à ética. Enquanto vinculado a esses princípios, o grande esforço de nossos guardiões da ética segue o risco de se reduzir a "repartições administrativas que emitirão carimbos e assinaturas sem os quais o mundo estaria na mesma situação ética em que sempre esteve." (SILVEIRA; HÜNING, 2010, p. 394)

Cabe, de modo especial às ciências humanas e sociais, provocar o deslocamento de investimentos políticos e intelectuais para desnaturalizar o modelo vigente e pensar alternativas. A análise apresentada por Fonseca (2015) aponta para caminhos possíveis a partir de experiências europeias, as quais, embora não possam ser idealizadas, indicam que é possível a inclusão de outros atores em um diálogo mais amplo e horizontal sobre a ética em pesquisa.

Reconhecer a situacionalidade assim como o caráter negociado das regras éticas seria uma estratégia para romper com a autoridade top-down dos especialistas e abrir espaços consequentes para a expressão das demandas e inquietações dos homens e mulheres - cidadãos comuns - mais afetados pela pesquisa (FONSECA, 2015, p. $352)$.

No Brasil, há um movimento liderado especialmente por associações de pesquisa e pós-graduação (Associação Nacional de Pós-Graduação e Pesquisa em Educação (ANPED); Associação Nacional de Pós-Graduação e Pesquisa em Ciências Sociais (ANPOCS); Associação Nacional de Pesquisa e Pós-graduação em Psicologia (ANPEPP); Associação Brasileira de Antropologia (ABA); entre outras), bem como pelo Fórum de Ciências Humanas, Sociais, Sociais Aplicadas, Letras e Artes (FCHSSALA), no sentido de criar um sistema de revisão e avaliação da ética na pesquisa nas CHS que não esteja subordinado ao Ministério da Saúde. Tal movimento busca atender de fato às especificidades dessas áreas de conhecimento, afastando-se do já mencionado "imperialismo biotético" (DUARTE, 2015, p. 31) que mesmo com as mudanças colocadas pela resolução 510/2016 do CNS, permeia as regulamentações e projetos de lei sobre ética na pesquisa com seres humanos (ver, por 
exemplo, PL 7082/2017, que tramita atualmente na Comissão de Constituição e Justiça e de Cidadania (CCJC).

De todo modo, trata-se ainda da criação de um sistema de regulação e, a despeito de sua importância, a reflexão apresentada ao longo deste artigo busca apontar para os limites desses sistemas e sustentar dois argumentos retomados aqui: a) que a ética não é passível de institucionalização e normalização; e b) que não é possível dissociar ética da política epistemológica da pesquisa. Cabe-nos, então, pensar em como operacionalizar um cuidado ético nas pesquisas e sua vinculação às políticas de produção de conhecimento.

No campo da formação e da prática acadêmica seria fundamental investirmos em uma ampliação do debate sobre ética destacando-se o caráter ético-político intrínseco a qualquer forma de produção de conhecimento. Esse tipo de estratégia é exatamente o oposto do que foi historicamente preconizado por uma ciência que recusou seu vínculo com a ética, porque se afirmava neutra, ou mesmo da que se promoveu com a ênfase colocada sobre os processos de institucionalização e normalização da ética por resoluções e comitês. A academia já é formada por uma infinidade de processos e instâncias de avaliação, especialmente voltadas ao chamado mérito científico. O que os sistemas institucionalizados e especializados na avaliação da ética na pesquisa alcançaram foi contribuir na dissociação da dimensão ética da científica. Defende-se aqui que é preciso enfrentar essa clivagem sem atribuir a um sistema externo a responsabilidade pela avaliação e regulação ética das pesquisas. Do modo como tem operado, o sistema CEP/CONEP tende a provocar nos pesquisadores maior preocupação com o atendimento à burocracia do que com o cuidado ético, que deveria ser indissociável de todas as etapas de realização de uma pesquisa, da elaboração de um projeto à divulgação de seus resultados.

No campo social, de modo mais amplo, é preciso induzir espaços de discussão sobre a ética na ciência, nos quais possam participar não apenas os atores envolvidos com sua produção, mas também seus destinatários. Nas pesquisas em CHS, particularmente, é comum que se adotem estratégias coletivas de delimitação de objetivos e estratégias de investigação, negociadas com comunidades ou grupos sociais específicos. Se isso é possível, se considerase que esses sujeitos ou grupos estão aptos a participar de tais decisões, por que não seria possível a análise da dimensão ética por esses mesmos coletivos? Trata-se de considerar participantes e destinatários das pesquisas como sujeitos capazes de dialogar sobre o conhecimento que se pretende produzir e os cuidados éticos requeridos.

Espaços desse tipo seriam questionadores de uma suposta superioridade moral dos pesquisadores, seja individualmente ou agrupados em comitês, reconhecendo-se que a ética é Barbarói, Santa Cruz do Sul, n. 56, p.<84-103>, jan./jun. 2020 
um campo aberto caracterizado fundamentalmente pela relação. Da forma como funcionam atualmente, as resoluções e comitês vigentes fragilizam isso que seria o imprescindível para a reflexão ética: o amplo debate na comunidade científica e fora dela sobre as políticas de pesquisa. É necessário, portanto, pensar a ética a partir de coletivos não institucionalizados, que envolvam mais do que participantes e pesquisadores, e promover sua constituição como alternativa ao modelo naturalizado dos comitês. Para isso, é preciso aproximar cada vez mais a reflexão ético-política da formação científica, destronando o saber e a autoridade dos experts, para pensar os sentidos e limites da produção de conhecimentos.

Tais considerações apontam para o que aqui se denomina de política epistemológica, ideia que se sustenta na compreensão de que nossas práticas de pesquisa constituem-se necessaria e simultaneamente pelas dimensões epistemológica, ética e política. A criação e a legitimação de diferentes perspectivas epistemológicas, dos discursos considerados válidos no campo científico, se dão num campo de condições de possibilidades (FOUCAULT, 2008) situadas de modo histórico, geográfico, temporal, político e cultural. Não há como estabilizar ou capturar tais processos, tampouco seria desejável, já que isso implicaria na limitação da própria ciência.

O reconhecimento destes atravessamentos na formação dos discursos científicos ou nas preocupações éticas, conecta e implica nossas práticas de pesquisa com a vida cotidiana e seus atores, para além das fronteiras tradicionalmente consideradas científicas. A afirmação de neutralidade, a primazia do método, a busca da verdade universal; ou, por outro lado, uma perspectiva assumidamente política, um conhecimento situado (HARAWAY, 1995) que no lugar do método inventa estratégias, que se faz de modo processual e dialógico com quem participa da pesquisa, dentre muitas outras possibilidades, constituem-se como políticas epistemológicas.

Assim, conclui-se que toda política epistemológica, traz consigo uma ética e uma visão sobre como essa pode ou deve ser regulada. Impor um modelo ético único à diversidade de posturas político-epistemológicas possíveis produz um reducionismo, tanto do que é a ética, quanto do que pode ser ciência. Manter aberto esse debate e recusar seu engessamento em sistemas externos e hegemônicos de controle e regulamentação é um movimento no sentido de buscar, também no campo político-científico, a prática da democracia. 


\title{
ETHICS AND RESEARCH POLICIES IN THE HUMAN AND SOCIAL SCIENCES
}

\begin{abstract}
In view of the publication of the Resolution $n^{\circ} 510 / 2016$ by the National Health Council, that regulates ethics in research with human beings in social and human sciences (SHS), this article proposes a reflection on the limits of thinking about ethics in research from the emphasis on the regulation and on the control of the research methodological procedures, dissociated from an epistemological policy. It is argued that our present regulation model reiterates the prevalence of a positivist and individualistic logic that has been often restrictive on research strategies and, many times, has led to the emptying of the ethical reflection. Moreover, the stiffening around bureaucratized procedures and regulations can also produce an erasing of differences between distinct theoretical and epistemological approaches in the SHS. In the face of those issues two main arguments are developed: a) that the ethics is not susceptible of institutionalization and normalization; and b) that it is not possible to dissociate ethics from research epistemological policy. This work concludes stating the need of an intellectual and political investment in the denaturalization of the current regulation model. In this regard, it indicates the importance of including other actors in a wider and horizontal dialogue on research ethics. It is suggested to think about ethics from non-institutionalized collectives that involve more than participants and researchers, and to promote their constitution as an alternative to the naturalized model of the committees. Simultaneously, it is necessary to expand the ethical-political reflection in the education and in the research practices in order to think about the senses and the limits of the scientific production.
\end{abstract}

Keywords: ethics, research, human and social sciences.

\section{ÉTICA Y POLÍTICAS DE INVESTIGACIÓN EN CIENCIAS HUMANAS Y SOCIALES}

\section{Resumen}

En vista de la publicación de la Resolución no 510/2016 del Consejo Nacional de Salud, que regula la ética de la investigación con seres humanos en las ciencias humanas y sociales (CHS), este artículo propone una reflexión sobre los límites de se pensar la ética en la investigación desde la énfasis en la regulación y el control de los procedimientos metodológicos de investigación, disociado de una política epistemológica. Se argumenta que nuestro modelo regulatorio actual reitera la prevalencia de una lógica positivista e individualista que, a menudo, ha sido restrictivo de estrategias de investigación y, muchas veces, condujeron al vaciado de la reflexión ética. Además, el endurecimiento en torno a los procedimientos burocráticos y reglamentos puede también borrar las diferencias entre los distintos enfoques teóricos y epistemológicos en CHS. En vista de estos problemas, se desarrollan dos argumentos principales: a) que la ética no está sujeta a institucionalización y normalización; y b) que no es posible disociar la ética de la política epistemológica de investigación. Se concluye afirmando la necesidad de una inversión intelectual y política en la desnaturalización del modelo regulatorio actual. En este sentido, se indica la importancia de incluir a otros actores en un diálogo más amplio y horizontal sobre ética de la investigación. Se sugiere pensar la ética desde colectivos no institucionalizados que involucran más que participantes e investigadores, y promover su constitución como alternativa al modelo naturalizado de los comités. Al mismo tiempo, es necesario ampliar la reflexión ético-política en la formación y en las prácticas de investigación para pensar sobre los significados y los límites de la producción científica.

Palabras-clave: ética, investigación, ciencias humanas y sociales. 


\section{REFERÊNCIAS}

CNS. CONSELHO NACIONAL DE SAÚDE. Resolução nº 510, de 7 de abril de 2016.

Diário Oficial da União, Brasília, 24 de maio de 2016, Seção 1, p. 44-46. Disponível em: <http://bvsms.saude.gov.br/bvs/saudelegis/cns/2016/res0510_07_04_2016.html> Acesso em: 13 nov. 2018.

DUARTE, Luiz Fernando Dias. Cronologia da luta pela regulação específica para as Ciências Humanas e Sociais da avaliação da ética em pesquisa no Brasil. Práxis Educativa, Ponta Grossa, v. 12, n.1, jan./abr. 2017.

. A ética em pesquisa nas ciências humanas e o imperialismo bioético no Brasil.

Revista Brasileira de Sociologia, Brasília, v. 3, n. 5, p. 29-52, jan./jun. 2015. DOI: 10.20336/rbs.90.

FONSECA, Claudia. Situando os comitês de ética em pesquisa: o sistema CEP (Brasil) em perspectiva. Horizontes Antropológicos, Porto Alegre, v. 21, n. 44, p. 333369, jul./dez. 2015. DOI: 10.1590/S0104-71832015000200014.

FOUCAULT. Michel. A Arqueologia do Saber (1969). Tradução de Luiz Felipe Baeta Neves. 7. ed. Rio de Janeiro: Forense Universitária, 2008.

GRUPO DE TRABALHO da Resolução sobre Ética em Pesquisa nas Ciências Humanas e Sociais. Carta Aberta de Resposta à "Carta da CONEP ao Grupo de Trabalho da Resolução sobre Ética em Pesquisa nas Ciências Humanas e Sociais (CHS)", de 28 de janeiro de 2015. Disponível em:

<http://www.sbponline.org.br/arquivos/CHS_resposta_do_GT_\%C3\%A0_CONEP.pdf> Acesso em: 13 nov. 2018.

HARAWAY, Donna. Saberes localizados: a questão da ciência para o feminismo e o privilégio da perspectiva parcial. Cadernos Pagu n.5, p. 7-41, 1995.

HARAYAMA, Rui Massato. Os novos desafios da etnografia: Para além da resolução n ${ }^{\circ}$ 510/2016. Revista Mundaú, Maceió, n. 2, p. 22-37, 2017. Disponível em: <http://www.seer.ufal.br/index.php/revistamundau/article/view/3022/2569> Acesso em: 13 nov. 2018.

OLIVEIRA, Marcos Barbosa de. A epidemia de más condutas na ciência: o fracasso do tratamento moralizador. Scientiae Studia, São Paulo, v. 13, n. 4, p. 867-897, set./dez. 2015. DOI: $10.1590 /$ S1678-31662015000400007.

SARTI, Cynthia. A ética em pesquisa transfigurada em campo de poder: notas sobre o sistema CEP/CONEP. Revista Brasileira de Sociologia, Brasília, v. 3, n. 5, p. 79-96, jan./jun. 2015. DOI: 10.20336/rbs.94.

SARTI, Cynthia; PEREIRA, Éverton Luís; MEINERZ, Nádia. Avanços da Resolução 510/2016 e impasses do sistema CEP-CONEP. Revista Mundaú, Maceió, n. 2, p. 8-21, 2017. Disponível em: 〈http://www.seer.ufal.br/index.php/revistamundau/article/view/3583/2579> Acesso em: 13 nov. 2018. 
SEVERINO, Antonio Joaquim. Ética e pesquisa: autonomia e heteronomia na prática científica. Cadernos de Pesquisa, São Paulo, v. 45, n. 158, p. 776-792, out./dez. 2015. DOI: $10.1590 / 198053143355$.

SILVEIRA, Ronie Alexsandro Teles da; HÜNING, Simone Maria. A tutela moral dos comitês de ética. Psicologia \& Sociedade, Florianópolis, v. 22, n. 2, p. 388-395, mai./ago. 2010. DOI: 10.1590/S0102-71822010000200020.

SILVEIRA, Ronie Alexsandro Teles da. Gambiarra ética. Psicologia em Estudo, Maringá, v. 18, n. 1, p. 169-173, jan./mar. 2013. DOI: 10.1590/S1413-73722013000100017.

SOUZA, Ricardo Timm de. Ética como fundamento: uma introdução à ética contemporânea. São Leopoldo: Nova Harmonia, 2004.

Data de recebimento: $20 / 02 / 2020$

Data de aceite: $21 / 05 / 2020$

\section{Sobre a autora:}

Simone Maria Hüning é Graduada em Psicologia pela UNISC; mestra e doutora em Psioclogia pela PUCRS; docente-pesquisadora do Programa de de Pós-Graduação em Psicologia da Universidade Federal de Alagoas (UFAL). Coordenadora do Grupo de Pesquisa "Processos culturais, políticas e modos de subjetivação". Bolsista PQ2 CNPq. Endereço Eletrônico: simone.huning@ip.ufal.br 